\title{
Proxy electrochemical process for Acid humic
}

\author{
G. Kashi ${ }^{1},{ }^{*}$, F. Khoshab ${ }^{1}$ \\ ${ }^{1}$ Department of Environmental Health, Islamic Azad University Tehran Medical Sciences \\ Branch, Tehran, Iran (E-mail: g.kashi@yahoo.com) \\ ${ }^{2}$ Water Purification Research, Department of Environmental Health Engineering, Islamic \\ Azad University Tehran Medical Sciences Branch, Tehran, Iran
}

\begin{abstract}
Humic substances are produced by the microbial degradation of dead plant matter. The goal of this research is to investigate of humic acid (HA) from urban drinking water by batch proxy electrochemical reactor(PER)with using zinc-copper electrode(distance $2 \mathrm{~cm}$ ) and hydrogen peroxide. The variables include $\mathrm{pH}(4-10)$, concentration of HA(5-15 $\mathrm{mg} / \mathrm{L})$, reaction time $(7.5-22.5 \mathrm{~min})$, concentration of hydrogen peroxide(40-120 $\mathrm{mg} / \mathrm{L})$, and current density $\left(3-9 \mathrm{~mA} / \mathrm{cm}^{2}\right)$. In electrochemical reactor, the removal percentage for $H A$ concentration $(5 \mathrm{mg} / \mathrm{L})$ in current density $9 \mathrm{~mA} / \mathrm{cm}^{2}$ and electrolysis time $15 \mathrm{~min}$ in $\mathrm{pHs} 4,7$, and 10 are obtained $61 \%, 56 \%$, and 51\%, respectively. In electrochemical reactor, the removal percentage for $H A$ concentration $(15 \mathrm{mg} / \mathrm{L})$ in current density $9 \mathrm{~mA} / \mathrm{cm}^{2}$ and electrolysis time $15 \mathrm{~min}$ in $\mathrm{pHs} 4,7$, and 10 are obtained $41 \%, 36 \%$, and $31 \%$, respectively. In PER, the removal percentage for HA concentration $(5 \mathrm{mg} / \mathrm{L})$, in optimum conditions, in hydrogen peroxide concentration $120 \mathrm{mg} / \mathrm{L}$, current density $9 \mathrm{~mA} / \mathrm{cm}^{2}$, optimum pH 4 , electrolysis time 15 min in HA concentrations 5, 10, and 15 are obtained $100 \%, 93 \%$, and 83\%, respectively. The findings indicate that HA removal efficiency is increased with increasing current density, electrolysis time, and decreasing HA concentration. PER has appropriate efficiency for the HA removal from water.
\end{abstract}

Keywords: Humic Acid, Hydrogen peroxide, Proxy electrochemical, Urban drinking watewor. 


\section{Introduction}

$\mathrm{H}$ Umiic acids (HA) is composed of aromatic molecules, linked with phenolic and carboxylic functional groups [1]. HA act as mixtures of dibasic acids, with a pK 1 value around 4 for protonation of carboxyl groups and around 8 for protonation of phenolate groups [2]. The high concentration of $\mathrm{HA}$ and fluvic acids $(>100 \mu \mathrm{g} / \mathrm{L})$ in treated drinking water result in forming toxic to humans disinfection byproducts (DPBs) such as dihaloacetonitriles, yellowish to brown color, irritating eye and skin, and damaging to human red blood cells [3]. HA results in injuring to human red blood. The guidline level for DPBs in drinking water is $100 \mu \mathrm{g} / \mathrm{L}$, according to the World Health Organization (WHO) [4]. The increase in natural organic materrs (NOMs) such as HA levels in ground and surface water have been mainly attributed to anthropogenic (the food, leather, and wood manufacturing) and natural (the microbial degradation of dead plant matter) sources [5]. The concentration of NOMs of Karaj, Jajrood, and Lar rivers is 11.33, 12.9, and 8.53 $\mathrm{mg} / \mathrm{L}$, respectively [6]. The conventional processes for HA removal are adsorption (such as husk ash, pillared bentonite), biodegradation, chemical precipitation (such as aluminium sulfate and organic polymers), ion exchange, membrane filteration, ozonation, and ultrasound waves [7]. High production chemical sludge is one of the disadvantages of chemical precipitation [8]. The most important disadvantage of coagulation method is the high concentration of residual aluminum in finished water. The most important disadvantage membrane separations are membrane fouling and degradation [9]. The main disadvantage of ion exchange is the high operating cost. Therefore removal method of HA needs to be very new, effective-cost. In recent years, advanced oxidation processes (AOPs) such as proxy electrochemical are applied for treating the HA-contaminated water [10]. Proxy electrochemical reactor (PER) process leads to production hydroxyl radicals $\left(\mathrm{OH}^{*}\right)$. This process is a combination of electric filed and hydrogen peroxide. This process is selective for HA removal and electron transfer reactions in electrode and water interface lead to mineralizing HA. External source of hydrogen peroxide is injected in to system [11]. Effective factors on the optimal performance of PER are: current density, water quality, the ratio of HA to reagents such as hydrogen peroxide, and turbidity amount [12]. The advantages of removal of HA by PER process are: clean treatment, high mineralization, and absent operational and maintenance problem [13]. Recent researchs have shown that PER technologies can propose a good opportunity to remove microbial and chemical pollutants. The application of electrochemical technologies develops in decay of organic oil [14], organic pollutants [15-16] In this study the coupling of hydrogen peroxide and the batch electrochemical reactor has introduced a new method to meeting a more efficient degradation of HA. The aim of this study is the degradation HA, a pollutant which was considered a pollutant tolerant to biodegradation, from drinking water using hydrogen peroxide and electrochemical batch reactor including zinc and copper electrodes. The studied variables are the HA concentration, the current density, the hydrogen peroxide concentration, the $\mathrm{pH}$, and the reaction time. This pollutant is studied as the model pollutant in this study.

\section{Materials and Methods}

\subsection{Preparation of water sample}

AH-contaminated water samples used for electrochemical experiments are obtained from urbane distribution system situated the site of a laboratory in Islamic Azad University Tehran Medical Sciences Branch in Tehran city. The samples are tested for the main physicochemical characteristics. The mean values of these water characteristics are presented in Table 1. 
Table 1: The main physicochemical characteristics of nitrate-contaminated urbane water

\begin{tabular}{lcll}
\hline Parameter & Unit & Value \\
\hline Calcium & $\begin{array}{c}\mathrm{mg} / \mathrm{L} \\
\mathrm{CaCO} 3 \\
\text { Dissolved }\end{array}$ & as & 162 \\
$\begin{array}{c}\mathrm{mg} / \mathrm{L} \\
\text { oxyen }\end{array}$ & & 8.05 \\
Nitrate & $\mathrm{mg} / \mathrm{L}$ & 9.5 \\
ORP & $\mathrm{mV}$ & 279 \\
pH & & 7.19 \\
Sulphate & $\mathrm{mg} / \mathrm{L}$ & & 93.8 \\
Temperature & ${ }^{\circ} \mathrm{C}$ & & 20 \\
Total & $\mathrm{mg} / \mathrm{L}$ & as & 122 \\
Alkalinity & $\mathrm{CaCO}_{3}$ & & \\
\hline
\end{tabular}

\subsection{Preparation of electrodes}

The weight of electrode is measured after washing with distilled water. The electrode is pre-treated by washing with detergent, tap water. The cleaned electrode is dried before immersing in the reactor in water [17].

\subsection{Experimental Set up}

The batch PER with monopole arrangement is a $360 \mathrm{ml}$ glass vessel $(10 \times 6 \times 6 \mathrm{~cm})$ (figure 1$)$. Materials of copper $(\mathrm{Cu})$, and zinc $(\mathrm{Zn})$ are used as anode and cathode electrodes. The area of each electrode is $36 \mathrm{~cm}^{2}(9 \times 4 \times 0.1 \mathrm{~cm})$. The distance between electrodes was adjusted to 2 $\mathrm{cm}$. The AC electrical source had maximum electrical power of $60 \mathrm{~W}$. To evaluate the effect of electrolysis, on the HA removal process, samples undergo with different HA (Merk, Germany) concentration (5-15 mg/L), different current density (3-9 $\left.\mathrm{mA} / \mathrm{cm}^{2}\right)$, different hydrogen peroxide (Merk, Germany) concentration (40-120 $\mathrm{mg} / \mathrm{L}$ ), different $\mathrm{pH}$ (ca. 4-10), and different times (7.5-22.5 min). Magnetic stirrer (AiKa, Germany) is used for homogeneous mixing of water samples (Figure 1). For each test, $200 \mathrm{~mL}$ of sample water is poured into the reactor. All tests are performed at laboratory temperature (20 $\left.{ }^{\circ} \mathrm{C}\right)$. Chloride acid and sodium hydroxide solutions (0.1 N) (Merk, Germany) are used for $\mathrm{pH}$ adjustment.

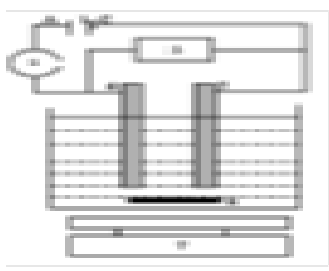

Figure 1: The batch PER

1. Power supply, 2. Current density (1-8 $\left.\mathrm{mA} / \mathrm{cm}^{2}\right)$, 3. Voltage volume (1-60 V), 4. Cathode electrode, 5. Anode electrode, 6 . Magnet, 7. Magnetic stirrer, 8. Hydrogen peroxide injector

\subsection{Analytical methods}

All tests are performed in triplicate, and the mean data values are reported. The water samples are tested for $\mathrm{HA}, \mathrm{ORP}, \mathrm{pH}$, and temperature after PER by using spectrophotometer (DR 5000, Hack, America), ORP-meter (CG, Malesia), pH-meter (Hack, America), respectively. The water samples are tested for HA after PER by using spectrophotometer (Hach DR5000, America) at a wavelength of $253.7 \mathrm{~nm}$. HA is determined according to procedure detailed in standard method 5910 B [18]. The percentage HA removal is calculated according to the following Eqn (1):

$$
R(\%)=[1-(C / C 0)] \times 100
$$

Where the percentage of HA removal ( $R$, percentage) and the HA value before and after treatment $\left(\mathrm{C}_{0}\right.$ and $\left.\mathrm{C}, \mathrm{mg} / \mathrm{L}\right)$ expressed.

The operational cost required to HA removal is calculated to the following Eqn (2):

$$
\text { operational cost }=C_{\text {energyt }}+C_{\text {electrod }}
$$

Where the operational cost (Coperational, Rial $\mathrm{kWh}$ per $\mathrm{kg}$ of HA removed), the consumed electrical energy cost (Cenergy, $\mathrm{kWh} / \mathrm{kg}$ ) and consumed electrode cost (Celectrode, Rial per $\mathrm{kg}$ of HA removed) expressed.

The electrical energy required to HA removal is calculated to the following Eqn (3):

$E E\left(\frac{k W h}{k g} A R 18\right.$ removed $\left.d \%\right)=\left(\frac{\text { VIt } \times 1000^{*}}{60 \times\left(C_{k 2}-C_{k}\right.}\right)$

Where the consumed electrical energy cost (EE, $\mathrm{kWh}$ per $\mathrm{kg}$ HA removed), the electrical voltage $(\mathrm{V}$, volt), the electrical current $(\mathrm{I}, \mathrm{A})$, and the electrochemical time $(\mathrm{t}, \mathrm{min})$ expressed.

Electrodes are rinsed with distilled water after conducting all tests. 


\section{Experimental Observations}

The results obtained from this study are shown below. The effects of HA concentration, current density, hydrogen peroxide concentration, $\mathrm{pH}$, and different times on the performance of proxy electrochemical reactor in HA removal from HA-contaminated urbane drinking water are investigated.

\subsection{Effect of AH concentration}

The effect of the initial concentration of HA on the removal efficiency of the PER process is shown in figure 2. The removal efficiency is decreased by an increase in the concentration from 5 to $15 \mathrm{mg} / \mathrm{L}$. The electrochemical reactor shows the removal percentage for HA concentration $(15 \mathrm{mg} / \mathrm{L})$ decreases from $48 \%$ to $38 \%$ as the $\mathrm{pH}$ increases from 4 to 10 , with 22.5 min reaction time and $9 \mathrm{~mA} / \mathrm{cm}^{2}$ current density (Tables 2-3). The removal percentage for HA concentration $(5 \mathrm{mg} / \mathrm{L})$ increases from $15 \%$ to $18 \%$ as the hydrogen peroxide concentration increased from 40 to $120 \mathrm{mg} / \mathrm{L}$, with $22.5 \mathrm{~min}$ of reaction time, and $\mathrm{pH} 4$ (Tables 5-7). The reaction time increases from $<7.5 \mathrm{~min}$ to $<22.5 \mathrm{~min}$ when the HA concentration increases from 5 to 15 $\mathrm{mg} / \mathrm{L}$, with current density $9 \mathrm{~mA} / \mathrm{cm}^{2}$, pH 4 (Table 8). The proxy electrochemical reactor shows increased from $83 \%$ to $100 \%$ as the reaction time increased $7.5 \mathrm{~min}$ to $22.5 \mathrm{~min}$, with HA concentration (15 mg/L), hydrogen peroxide concentration $(120 \mathrm{mg} / \mathrm{L})$, current density 9 $\mathrm{mA} / \mathrm{cm}^{2}$, and optimum $\mathrm{pH} 4$.

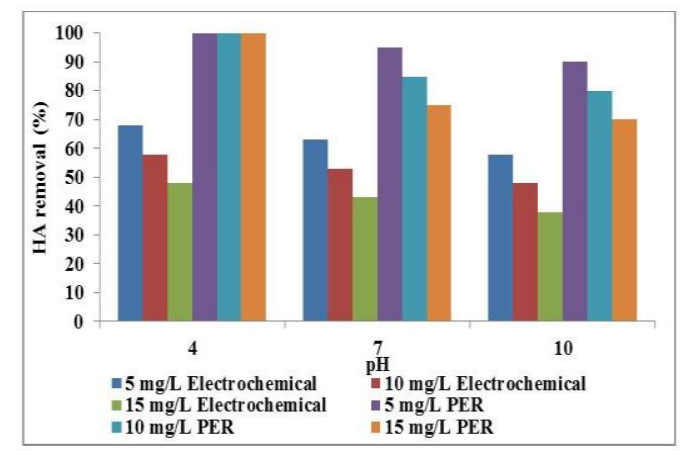

Figure 2: Effect of the initial concentration of $\mathrm{HA}$ and $\mathrm{pH}$ on efficiency of HA removal $(\mathrm{pH}$ 410; Temperature $25^{\circ} \mathrm{C}$; Reaction time $22.5 \mathrm{~min}$; Initial concentration 5-15 mg/L; Current density $9 \mathrm{~mA} / \mathrm{cm}^{2}$; Hydrogen peroxide concentration $120 \mathrm{mg} / \mathrm{L})$

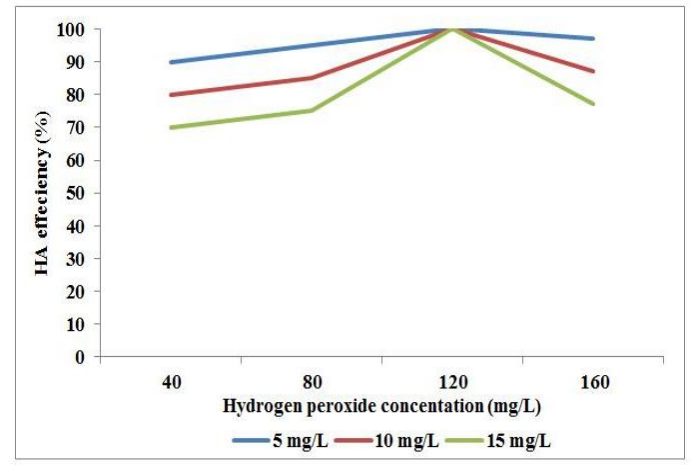

Figure 3: Effect of the initial concentration of hydrogen peroxide on efficiency of HA removal ( $\mathrm{pH} 4$; Temperature $25^{\circ} \mathrm{C}$; Reaction time 22.5 min; Current density $9 \mathrm{~mA} / \mathrm{cm}^{2}$ )

Table 2: Effect of electrochemical on HA removal from urban drinking water in $\mathrm{pH} 4$

\begin{tabular}{cccccccccc}
\hline $\begin{array}{c}\text { Current } \\
\text { density } \\
\left(\mathrm{mA} / \mathrm{cm}^{2}\right)\end{array}$ & $\begin{array}{c}\text { HA concentration } 5 \mathrm{mg} / \mathrm{L} \\
(\%)\end{array}$ & \multicolumn{3}{c}{$\begin{array}{c}\text { HA concentration } 10 \mathrm{mg} / \mathrm{L} \\
(\%)\end{array}$} & \multicolumn{3}{c}{$\begin{array}{c}\text { HA concentration } 15 \mathrm{mg} / \mathrm{L} \\
(\%)\end{array}$} \\
\hline & 7.5 & 15 & 22.5 & 7.5 & 15 & 22.5 & 7.5 & 15 & 22.5 \\
3 & 50 & 55 & 58 & 40 & 45 & 48 & 30 & 35 & 38 \\
6 & 56 & 60 & 63 & 46 & 50 & 53 & 36 & 40 & 43 \\
9 & 61 & 66 & 68 & 51 & 56 & 58 & 41 & 46 & 48 \\
\hline
\end{tabular}

Table 3: Effect of electrochemical on HA removal from urban drinking water in $\mathrm{pH} 7$

\begin{tabular}{|c|c|c|c|c|c|c|c|c|c|}
\hline \multirow{2}{*}{$\begin{array}{c}\text { Current } \\
\text { density } \\
\left(\mathrm{mA} / \mathrm{cm}^{2}\right)\end{array}$} & \multicolumn{3}{|c|}{$\begin{array}{l}\text { HA concentration } 5 \mathrm{mg} / \mathrm{L} \\
(\%)\end{array}$} & \multicolumn{3}{|c|}{$\begin{array}{l}\text { HA concentration } 10 \mathrm{mg} / \mathrm{L} \\
(\%)\end{array}$} & \multicolumn{3}{|c|}{$\begin{array}{l}\text { HA concentration } 15 \mathrm{mg} / \mathrm{L} \\
(\%)\end{array}$} \\
\hline & \multicolumn{3}{|c|}{ Time $(\min )$} & \multicolumn{3}{|c|}{ Time (min) } & \multicolumn{3}{|c|}{ Time $(\min )$} \\
\hline & 7.5 & 15 & 22.5 & 7.5 & 15 & 22.5 & 7.5 & 15 & 22.5 \\
\hline 3 & 45 & 50 & 53 & 35 & 40 & 43 & 25 & 30 & 33 \\
\hline 6 & 51 & 55 & 58 & 41 & 45 & 48 & 31 & 35 & 38 \\
\hline 9 & 56 & 61 & 63 & 46 & 51 & 53 & 36 & 41 & 43 \\
\hline
\end{tabular}

Table 4: Effect of electrochemical on HA removal from urban drinking water in $\mathrm{pH} 10$ \begin{tabular}{cccccccccc}
\hline $\begin{array}{c}\text { Current } \\
\text { density } \\
\left(\mathrm{mA} / \mathrm{cm}^{2}\right)\end{array}$ & $\begin{array}{c}\text { HA concentration } 5 \mathrm{mg} / \mathrm{L} \\
(\%)\end{array}$ & \multicolumn{3}{c}{$\begin{array}{c}\text { HA concentration } 10 \mathrm{mg} / \mathrm{L} \\
(\%)\end{array}$} & \multicolumn{3}{c}{$\begin{array}{c}\text { HA concentration } 15 \mathrm{mg} / \mathrm{L} \\
(\%)\end{array}$} \\
\hline & 7.5 & 15 & 22.5 & 7.5 & 15 & 22.5 & 7.5 & \multicolumn{3}{c}{ Time $(\mathrm{min})$} \\
\hline 3 & 40 & 45 & 48 & 30 & 35 & 38 & 20 & 25 \\
\hline 6 & 46 & 50 & 53 & 36 & 40 & 43 & 26 & 30 & 28 \\
\hline 9 & 51 & 56 & 58 & 41 & 46 & 48 & 31 & 36 & 38 \\
\hline
\end{tabular}

Table 5: Effect of hydrogen peroxide on HA removal from urban drinking water in $\mathrm{pH} 4$

\begin{tabular}{cccccccccc}
\hline $\begin{array}{c}\text { Concentration } \\
(\mathrm{mg} / \mathrm{L})\end{array}$ & $\begin{array}{c}\text { HA concentration } 5 \mathrm{mg} / \mathrm{L} \\
(\%)\end{array}$ & $\begin{array}{c}\text { HA concentration } 10 \mathrm{mg} / \mathrm{L} \\
(\%)\end{array}$ & \multicolumn{2}{c}{$\begin{array}{c}\text { HA concentration } 15 \mathrm{mg} / \mathrm{L} \\
(\%)\end{array}$} \\
\cline { 2 - 11 } & \multicolumn{3}{c}{ Time (min) } & \multicolumn{3}{c}{ Time (min) } & \multicolumn{3}{c}{ Time (min) } \\
\hline & 7.5 & 15 & 22.5 & 7.5 & 15 & 22.5 & 7.5 & 15 & 22.5 \\
\hline 40 & 12 & 13 & 15 & 10 & 12 & 13 & 8 & 10 & 12 \\
\hline 80 & 13.5 & 15.5 & 17 & 12.5 & 13.5 & 14 & 10.5 & 12.5 & 13 \\
\hline 120 & 16 & 17.5 & 18 & 14.5 & 15.5 & 16 & 13 & 14 & 15 \\
\hline
\end{tabular}

Table 6: Effect of hydrogen peroxide on HA removal from urban drinking water in $\mathrm{pH} 7$

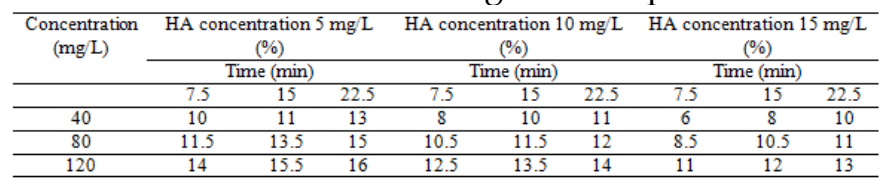

Table 7: Effect of hydrogen peroxide on HA removal from urban drinking water in $\mathrm{pH} 10$ 


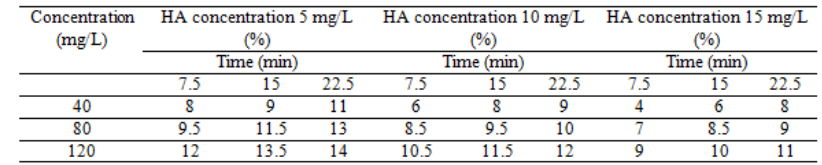

Table 8: Effect of PER on HA removal from urban drinking water in $\mathrm{pH} 4$

\begin{tabular}{cccccccccc}
\hline $\begin{array}{l}\text { Current } \\
\text { density } \\
\left(\mathrm{mA} / \mathrm{cm}^{2}\right)\end{array}$ & $\begin{array}{c}\text { HA concentration } 5 \mathrm{mg} / \mathrm{L} \\
(\%)\end{array}$ & \multicolumn{3}{c}{$\begin{array}{c}\text { HA concentration } 10 \mathrm{mg} / \mathrm{L} \\
(\%)\end{array}$} & \multicolumn{3}{c}{$\begin{array}{c}\text { HA concentration } 15 \mathrm{mg} / \mathrm{L} \\
(\%)\end{array}$} \\
\hline & 7.5 & 15 & 22.5 & 7.5 & 15 & 22.5 & 7.5 & 15 & 22.5 \\
\hline 3 & 91 & 96 & 100 & 81 & 86 & 90 & 71 & 76 & 80 \\
\hline 6 & 100 & 100 & 100 & 90 & 95 & 99 & 80 & 85 & 89 \\
\hline 9 & 100 & 100 & 100 & 97 & 100 & 100 & 87 & 93 & 100 \\
\hline
\end{tabular}

\subsection{Effect of water $\mathrm{pH}$}

Electrochemical experiments are carried out an initial $\mathrm{pH}$ values in the range of 4 to 10 . The results are indicated in figure 3 . In the electrochemical and PER, the mean HA removal increases in optimum $\mathrm{pH} 4$ when the HA concentration increases from 5 to $15 \mathrm{mg} / \mathrm{L}$.

\subsection{Effect of current density}

The effect of the current density on the removal efficiency of the PER process is shown in figure 4 . The optimum current density for reaching to HA standard is $9 \mathrm{~mA} / \mathrm{cm}^{2}$, with optimum $\mathrm{pH}$ 4. At lower current density, lower reaction time, and lower hydrogen peroxide concentration the removal efficiency of HA (5-15 $\mathrm{mg} / \mathrm{L}$ ) starts to lessen (Tables 2-8 and figure 4). The optimum hydrogen peroxide concentration for reaching to HA standard is $120 \mathrm{mg} / \mathrm{L}$, with pHs 4,7 , and 10 .

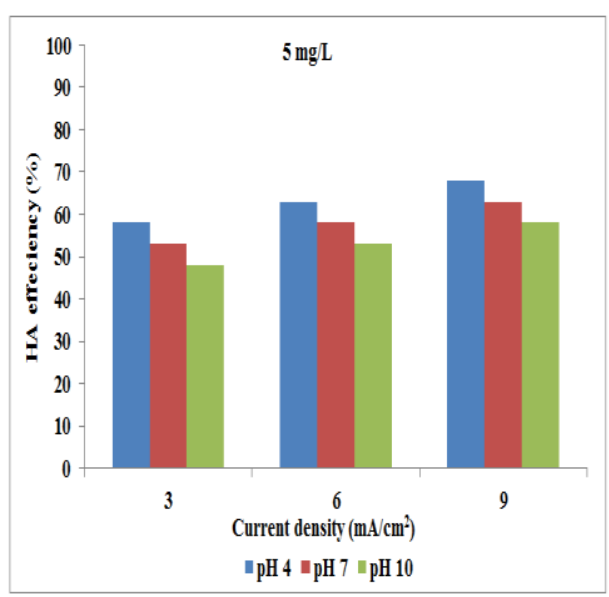

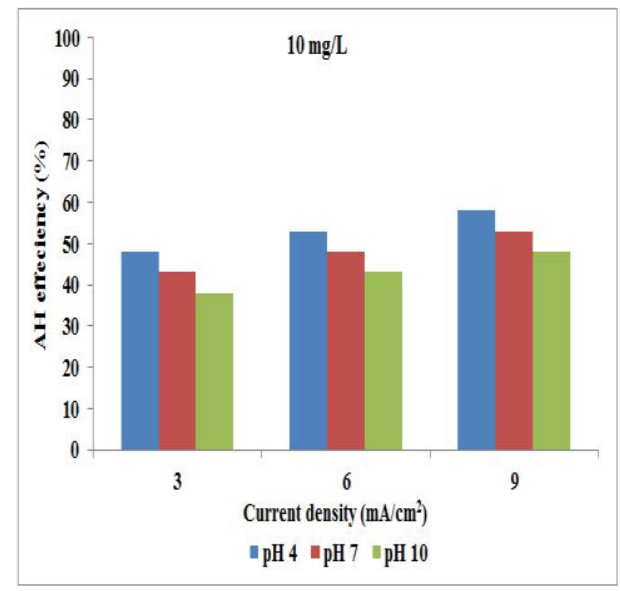

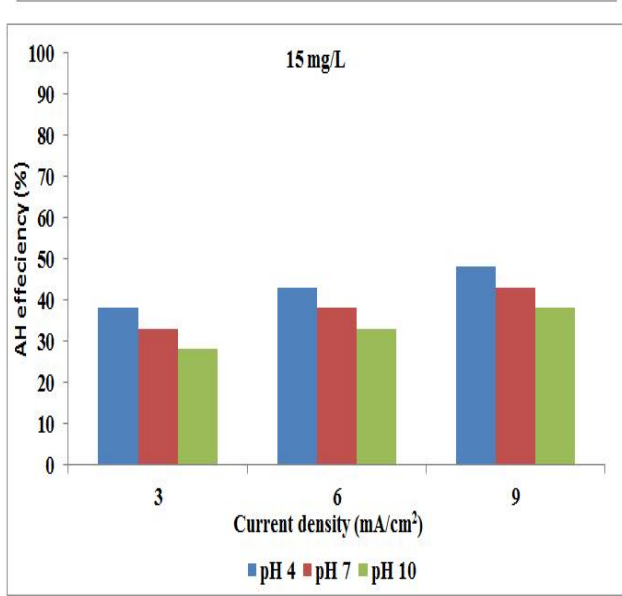

Figure 4: Effect of the current density on efficiency of HA removal ( $\mathrm{pH}$ 4-10; Temperature $25^{\circ} \mathrm{C}$; Reaction time $22.5 \mathrm{~min}$; Initial concentration 5-15 mg/L)

\section{Discussion}

HA removal in the PER is seriously affected by the concentration, and $\mathrm{pH}$ of sample. This effect is attributed to an increase in the HA clusters, a decrease in the rate of HA entering to the anode surface, and a decrease in the rate of HA oxidation reaction in the PER at a higher HA concentration. It is included that electrolysis leads to increasing the production of hydrogen. This phenomenon is the same as humic-like subestances (HLS) from wastewater. Kliagaite et al. [19] are investigated the effect of electrochemical degradation on HLS. These experiments are performed an initial paper and board industry flow rate in the range of 2 to 40 $\mathrm{mL} / \mathrm{min}$ at, and voltage in the range of 5 to $20 \mathrm{~V}$. At higher flow rate, the efficiency starts to lessen.

The degradation effect of this method is strongly dependent on $\mathrm{pH}$, and is enhanced by a decrease in $\mathrm{pH}$. In the PER process, different concentrations of hydrogen $\left(\mathrm{H}_{2}\right)$ from water are 
formed depending on the $\mathrm{pH}$. These products play an important role in the removal of HA concentrations in the PER process. This effect is attributed to an increase in the availability of $\mathrm{OH}^{-}$anion at a lower $\mathrm{pH}$ that generates more $\mathrm{H}_{2}$ bubbles. The decrease in HA removal at $\mathrm{pH} 10$ can be attributed to increasing the oxidation of hydroxide anion in the anode. The optimum (the best) $\mathrm{pH}$ for reaching to HA standard $(65 \mu \mathrm{g} / \mathrm{L})$ is 4 . The above increased mineralization activity is explained by higher formation of reactive oxygen species (ROS) in in the reactor due to accelerating the mass transfer by electron migration of the HA towards the electrode. The part of negatively charged HA molecule is transferred from cathode electrode to anode electrode. This finding is in agreement with previously published data by Cheng et al [20]. These electro-Fenton experiments are performed with a $\mathrm{Ce} / \mathrm{SnO}_{2}-\mathrm{Sb}$-coated titanium anode for the mineralization of metronidazole. They are informed that the optimum $\mathrm{pH}$ is 2. Sue et al [21] investigate the effect of a electro-Fenton process removal on acetaminophen. They are informed that the optimum $\mathrm{pH}$ is 4 . Bazrafshan et al [22] investigat the effect of an electrolysis system degradation on HA. They are informed that the optimum $\mathrm{pH}$ is 5 . This effect is attributed to a decrease in the reduction potential of reactor at an acidic $\mathrm{pH}$ that generated more $\mathrm{OH}^{\cdot}$ radicals.

A key variable parameter affecting the oxidation ability of PER is the applied current density since it regulates the amounts of generated $\mathrm{OH}^{-}$radicals acting as oxidizing agents. At higher current density, the radiation time starts to lessen. The degradation efficiency is proportional to the current density and the reaction time. Therefore, the current density fluctuations lead to measuring of the HA mineralization rate. The initial and final $\mathrm{pH}$ values are measured in this study in order to investigate the effect of $\mathrm{pH}$ more effectively. The initial $\mathrm{pH}$ enhances from 4.50 to 5.60 when the current density enhanced from 3 to $9 \mathrm{~mA} / \mathrm{cm}^{2}$, at reaction time $22.5 \mathrm{~min}, \mathrm{pH} 4$, and $\mathrm{HA}$ concentration $15 \mathrm{mg} / \mathrm{L}$ during PER studies. This finding is in agreement with previously published data by Katal and Pahlavanzadeh [23]. The higher current density and reaction time lead to improving the removal efficiency by higher formation of ROS such as hydrogen peroxide in the reactor due to consuming anode.
This finding is in agreement with previously published data by Yazdanbakhsh et al [24]. These proxy electrocoagulation process (PEP) experiments are performed at reaction time 20 $\mathrm{min}$, and the removal efficiency decreases from 98 to lower than $98 \%$ when the current density enhances from 1 to $2 \mathrm{~A} / \mathrm{cm}^{2}$. At current density more than $20 \mathrm{~mA} / \mathrm{cm}^{2}$, the removal efficiency starts to lessen by higher temperature in the reactor due to disintegrating $\mathrm{OH}^{*}$ radicals. This finding is in agreement with previously published data by Farhadi et al [25]. These experiments show that The COD removal efficiency is increased to $32 \%$ at $1.83 \mathrm{~mA} / \mathrm{cm}^{2}$ from $12 \%$ at $0.43 \mathrm{~mA} / \mathrm{cm}^{2}$ after $30 \mathrm{~min}$ reaction time. This electrochemical mechanism by copper (anode) and zinc (cathode) electrodes is illustrated in the following equations:

Anode: $4 \mathrm{OH}^{-} \leftrightarrow \mathrm{O}_{2}+2 \mathrm{H}_{2} \mathrm{O}+4 \mathrm{e}^{-}$

Anode: $3 \mathrm{H}_{2} \mathrm{O} \leftrightarrow 3 \mathrm{H}_{2}+\mathrm{O}_{3}$

Anode: $\mathrm{H}_{2} \mathrm{O} \leftrightarrow \mathrm{H}^{+}, \mathrm{H}_{2} \mathrm{O}_{2},{ }^{\circ} \mathrm{OH}$

Anode: $2 \mathrm{OH}^{-}+\mathrm{Cl}^{-} \leftarrow \mathrm{ClO}-+\mathrm{H}_{2} \mathrm{O}+2 \mathrm{e}^{-}$

Cathode: $2 \mathrm{H}_{2} \mathrm{O}+2 \mathrm{e}^{-} \leftrightarrow \mathrm{H}_{2} \mathrm{O}+2 \mathrm{OH}^{-}$

Cathode: $\mathrm{O}_{2}+2 \mathrm{H}^{+}+2 \mathrm{e}^{-} \leftrightarrow \mathrm{H}_{2} \mathrm{O}_{2}$

$\mathrm{HClO}+\mathrm{HA} \leftarrow \mathrm{CO}_{2}+\mathrm{H}_{2} \mathrm{O}+$ Products

It can be concluded that the maximum HA $(15 \mathrm{mg} / \mathrm{L})$ removal is at reaction time $22.5 \mathrm{~min}$, $\mathrm{pH}$ 4, hydrogen peroxide concentration 120 $\mathrm{mg} / \mathrm{L}$, and current density $9 \mathrm{~mA} / \mathrm{cm}^{2}$. The increase in hydrogen peroxide concentration from 40 to $120 \mathrm{mg} / \mathrm{L}$ increases HA (15 mg/L) removal from 70 to $100 \%$, and the increase in hydrogen peroxide concentration from 120 to $160 \mathrm{mg} / \mathrm{L}$ decreases HA $(15 \mathrm{mg} / \mathrm{L})$ removal from 100 to $77 \%$, at reaction time $22.5 \mathrm{~min}$. This effect is attributed to an inhibitory in the production $\mathrm{OH}$ radical. This finding is in agreement with previously published data by Dehghani et al [26]. They show that when the hydrogen peroxide concentration increases from 300 to $1000 \mathrm{mg} / \mathrm{L}$ the chemical oxygen demand removal decreased from to $28 \%$. According to optimum conditions (electrical current $0.01 \mathrm{~A}$, electrical potential $10 \mathrm{~V}$, reaction time $22.5 \mathrm{~min}$, hydrogen peroxide $120 \mathrm{mg} / \mathrm{L}$, and water need $40 \mathrm{~L} /$ day), it is calculated that the minimum operational cost of the PER is HA concentration $5 \mathrm{mg} / \mathrm{L}$ with removal efficiency $100 \%(845=120$ (consumed electrode cost) +725 (consumed electrical energy cost)) and the maximum operational cost of the PER is HA concentration 
$15 \mathrm{mg} / \mathrm{L}$ with removal efficiency $80 \%$ (1386 = 480 (consumed electrode cost) +906 (consumed electrical energy cost)). Therefore, at higher efficiency, the operational cost starts to lessen. This finding is in agreement with previously published data by Zaied and Bellakhal [27]. These experiments show that the calculated energy consumption is $1.4 \mathrm{kWh}$ for $1 \mathrm{~kg}$ removed COD (initial COD concentration $8 \mathrm{~g} / \mathrm{l}$ ) during an electrocoagulation reactor.

\section{Conclusions}

The experimental results suggest that batch PER is a practical and promising method for the HA-contaminated water. The PER is more effective than electrochemical reactor. HA degradation is affected by $\mathrm{pH}$, the concentration of AR 18, the concentration of hydrogen peroxide, reaction time, and current density. The PER are capable of HA removal at the $\mathrm{pH}$ value (4), with a reaction time less than 22.5 min. Enhanced HA removal is obtained with an increase in the hydrogen peroxide concentration, reaction time, and current density. It is purposed that performance of process is studied the other electrode material.

\section{Acknowledgment}

This research is conducted at water purification research center (WPRC). The authors like to thank the WPRC and Department Environmental Health Engineering of Azad Islamic University Medical Sciences Branch for financial and instrumental supports.

\section{References}

[1] Hafiz Muhammad, A., Syed Nadir, H., Edward Pelham, LR., Nigel, WB. (2013). Removal of humic acid from water using adsorption coupled with electrochemical regeneration. Korean Journal of Chemical and Engineering, 30 (7), 1415-1422.

[2] Hartono, T., Wang, S., Ma, Q., Zhu, Z. (2009). Layer structured graphite oxide as a novel adsorbent for humic acid removal from aqueous solution. Journal of Colloidal Interface Science, 333, 114-119.
[3] Wu, Y., Zhoua, Sh., Ye, X., Zhao, R., Chen, D. (2011). Oxidation and coagulation removal of humic acid using Fenton process. Colloids and Surfaces A: Physicochemical and Engineering Aspects, 379 (1), 151-155.

[4] World Health Organization. (2008). Guidelines for Drinking-water Quality, 3th ed. Geneva.

[5] Gulser, F., Sonmez, F., Boysan, S. (2010). Effects of calcium nitrate and humic acid on pepper seedling growth under saline condition. Journal of Environmental Biology, 31, 873-876.

[6] Zazouli, M., Nasseri, S., Mesdaghinia, A. (2008). Study of Natural Organic Matter Characteristics and Fractions in Surface Water Resources of Tehran. Iranian Journal of Health and Environment, 1 (1),1-7.

[7] Mahvi, AH., Maleki, A., Rezaee, R., Safari, M. (2009). Reduction of humic substances in water by application of ultrasound waves and ultraviolet irradiation. Iranian Journal Environmental Health Science Engineering, 6 (4), 233-240.

[8] Rezaie, R., Maleki, A., Shirzad Siboni, M., Rahimi, M., Mohammadi, M. (2011). Comparison of efficiency of photochemical and sonochemical processes combined with hydrogen peroxide in removal of direct blue 71 (D71) from aqueous solution. Journal of Kurdistan University of Medical Sciences, 16, 38-47.

[9] Sutzkover-Gutman, I., Hasson, D., Semiat, R. (2010). Humic substances fouling in ultrafiltration processes. Desalination, 261, p. 218-231.

[10] Arsene, D., Petronela Musteret, C., Catrinescu, C., Apopei, P., Brajoveanu, G., Teodosiu, C. (2011). Combined oxidation and ultrafilteration processes for the removal of priority organic pollutants from wastewaters. Journal of Environmental Engineering and Management, 10, 1967-1976.

[11] Ben, W., Qiang, Z., Pan, X., Chen, M. (2009). Removal of veterinary antibiotics from sequencing batch reactor (SBR) pretreated swine wastewater by Fenton's reagent. Water Rresearch, 43 (17), 4392-4402. 
[12] Khumsiri, N., Jindal, R., Yoswathana, N., Jonglertjunya, W. (2010). Kasets Journal (National Science) 44, 5 (4), 343-354

[13] Barbusinski, K. (2009). Fenton reactioncontroversy concerning the chemistry. Ecology Chemical Engineering, 42, 347-358.

[14] Ugurlu, M., Kula, I., Gurses, A. (2006). Removal of some organic compounds and color from olive mill wastewater by electrocoagulation. Fresenius Environmental Bulletin, 15, 1256-1265.

[15] Contreras, J., Villarroel, M., Navia, R., Teutli, M. (2009). Treating landfill leachate by electrocoagulation. Waste Management and Research, 27, 534-541.

[16] Misra, R., Gedam, N., Waghmare, S., Masid, S., Neti, NR. (2009). Landfill leachate treatment by the combination of physicochemical and electrochemical methods. Journal of Environmental Science and Engineering, 51, 315-320.

[17] Moussavi, G., Khosravi, R., Farzadkia, M. (2011). Removal of petroleum hydrocarbons from contaminated groundwater using an electrocoagulation process: Batch and continuous experiments. Desalination, 278, 288-294.

[18] HAPA, AWWA, WEF. (2012). Standard methods for the examination of water and wastewater. 22th ed. Washington DC: APHA.

[19] Kliaugaite, D., Yasadi, K., Euverink, GJ., F.M. Bijmans, M., Racys, V. (2013). Electrochemical removal and recovery of humic-like substances from wastewater. Separation and Purification Technology, 108, 37-44.

[20] Cheng, W., Yang, M., Xie, Y., Liang, B., Fang, Z., Tsang, EP. (2013). Enhancement of mineralization of metronidazole by the electro-Fenton process with a $\mathrm{Ce} / \mathrm{SnO} 2-\mathrm{Sb}$ coated titanium anode. Chemical Engineering Journal, 220, 214-220.
[21] Su, C.C., Chang, AT., Bellotindos, LM., Lu, MC. (2012). Degradation of acetaminophen by Fenton and electro- Fenton processes in aerator reactor. Separation Purification Technology, 99, 8-13.

[22] Bazrafshan, E., Biglari, H., Mahvi, AH. (2012). Humic acid removal from aqueous environments by electrocoagulation process using iron electrodes. E-Journal of Chemistry, 9 (4), 2453-2461.

[23] Katal, R., Pahlavanzadeh, H. (2011). Influence of different combinations of aluminum and iron electrode on electrocoagulation efficiency: Application to the treatment of paper mill wastewater. Desalination, 265 (1-3), 199-205.

[24] Yazdanbakhsh, AR., Kermani, M., Komasi, S., Aghayani, E., Sheikhmohammadi. A. (2015). Humic acid removal from aqueous solutions by peroxi-electrocoagulation process. Environmental Health Engineering and Management Journal, 2 (2), 53-58.

[25] Farhadi, S., Aminzadeh, B., Torabian, A., Khatibikamal, V., Fard, MA. (2012). Comparison of COD removal from pharmaceutical wastewater by electrocoagulation, photoelectrocoagulation, peroxi-electrocoagulation and peroxiphotoelectrocoagulation processes. Journal Hazardous Matererial, 219-220, 35-42.

[26] Dehghani, H., Jonidi jafari, A., Farzadkia, M., Gholami, M. (2012). Investigation of the efficiency of Fenton's advanced oxidation process in sulfadiazine antibiotic removal from aqueous solutions. Arak Medical University Journal, 15 (66), 19-29.

[27] Zaied, M., Bellakhal, N. (2009). Electrocoagulation treatment of black liquor from paper industry. Journal of Hazardous Materials, 163, 995-1000. 